\title{
Telomere length, proviral load and neurologic impairment in HTLV-1-and HTLV-2-infected humans
}

\author{
Benjamin Usadi ${ }^{1,2}$, Roberta Bruhn ${ }^{1}$, Jue Lin ${ }^{3}$, Tzong-Hae Lee', Elizabeth Blackburn ${ }^{3}$, Edward L Murphy ${ }^{3, *^{*}}$ \\ From 16th International Conference on Human Retroviruses: HTLV and Related Viruses \\ Montreal, Canada. 26-30 June 2013
}

\section{Background}

Telomeres shorten with aging and short or damaged telomeres have been implicated in degenerative conditions. We hypothesized that telomere length might be altered in chronic HTLV-1 and -2 infection and could be a marker of HTLV-associated disease and viral dynamics.

\section{Methods}

45 HTLV-1, 45 HTLV-2, and 45 seronegative subjects were selected from the larger HTLV Outcomes Study (HOST) cohort, and stratum-matched on age, sex and race/ethnicity. The telomere-to-single copy gene (T/S) ratio and HTLV-1 and -2 proviral load were measured using real-time PCR on the same PBMC samples. Unpaired t-tests, linear regression and logistic regression were used to test associations.

\section{Results}

Ln T/S ratio was inversely associated with age among seronegatives $(\mathrm{p}=.006)$ but HTLV-1 and -2 subjects did not show an inverse age association. There was no difference in mean T/S ratio between HTLV-1 (1.02), HTLV-2 (1.03) and matched seronegative (0.99) subjects. In HTLV-1 subjects, there was a borderline inverse association $(\mathrm{p}=0.07)$ between $\mathrm{T} / \mathrm{S}$ ratio and $\log 10$ proviral load which did not persist after multivariate adjustment $(\mathrm{p}=0.17)$. Among HTLV-2 subjects only, Ln T/S ratio was significantly associated $(\mathrm{p}=0.026)$ with increased odds of vibration-sensation impairment.

\section{Conclusions}

We found no evidence for an overall difference in telomere length between HTLV cases and controls but

${ }^{3}$ University of California San Francisco, San Francisco, CA, USA Full list of author information is available at the end of the article there was a weak association between HTLV-1 proviral load and telomere length. The association between telomere length and impaired vibration sense in the HTLV2-positive group is intriguing, and suggests avenues for future investigation of previously described neuropathy in that group.

\section{Authors' details}

'Blood Systems Research Institute, San Francisco, CA, USA. ${ }^{2}$ University of California, Berkeley, Berkeley, CA, USA. ${ }^{3}$ University of California San Francisco, San Francisco, CA, USA.

Published: 7 January 2014

doi:10.1186/1742-4690-11-S1-015

Cite this article as: Usadi et al:: Telomere length, proviral load and neurologic impairment in HTLV-1-and HTLV-2-infected humans. Retrovirology 2014 11(Suppl 1):O15.

Submit your next manuscript to BioMed Central and take full advantage of:

- Convenient online submission

- Thorough peer review

- No space constraints or color figure charges

- Immediate publication on acceptance

- Inclusion in PubMed, CAS, Scopus and Google Scholar

- Research which is freely available for redistribution 